\title{
ENERGY BALANCE STUDY OF WATER PONDS AND ITS INFLUENCE ON BUILDING ENERGY CONSUMPTION
}

\author{
Mirela Robitu ${ }^{1}$, Christian Inard ${ }^{2}$, Marjorie Musy ${ }^{1}$, Dominique Groleau ${ }^{1}$ \\ ${ }^{1}$ CERMA- Ecole d'Architecture de Nantes, 44319 Nantes, France \\ ${ }^{2}$ LEPTAB- Université de La Rochelle, 17042 La Rochelle, France
}

\begin{abstract}
$\underline{\text { ABSTRACT }}$
This study investigates the energy exchanges occurring in the volume and on the surface of water ponds and their influence on energy consumption of building. The mathematical model of water ponds is based on coupling the thermal model of the water pond and the airflow model of the surrounding air. It accounts for the heat transfer by radiation, conduction, convection and the latent heat transfer due to water evaporation. The governing equations are numerically solved by a finite difference method for the thermal model and by a finite volume method for the air flow model. The surface temperature and the spatial profiles of temperature and moisture are presented. The effect of the water pond on the cooling energy consumption is discussed.
\end{abstract}

\section{INTRODUCTION}

In recent years, the microclimatic problems, occurring in large cities, have been the subject of detailed attention. One of the most known of them is the urban heat island phenomenon, which consists in increased temperature downtown compared to the surrounding countryside (Oke 1982). The geographical situation and the structure of the city, i.e. regional meteorology, geometrical configuration, building materials, vegetation, water and human activities, have important influences on the urban climate (Mestayer and Anquetin 1994).

An adequate urban planning can have benefits such as thermal and visual comfort, reduction of health risks, and energy saving for air conditioning, which finally improve life quality (Bruse 1999). To improve urban climate, climatologists proposed to planners more strategies: less mineralization, more vegetation, higher albedo by choosing less absorbing materials and colours (Akbari et al. 1992, Givoni 1991) or water ponds favouring the evaporative cooling. These strategies enable us to modify the climatic impact of urban structures.

From ancient times, evaporative cooling is one of the most effective ways of passive cooling for buildings and urban spaces in hot regions (Ken-Ichi 1991). However, the effects of these actions are, to date, not easily measurable. Although we generally agree on their positive impact on urban climate, the measurement and the quantification of these effects remain delicate and limited. One important reason of this situation is mainly the complexity of the phenomena concerned and the difficulty of obtaining rigorous and reliable physical models connecting the physical parameters of the urban microclimate and the urban factors (form, materials, space, etc.).

The purpose of this study, pursuing the work already undertaken in a previous research (Vinet 2000), is to develop models and tools for simulating the phenomena in outdoor environment. In particular, we present here the development of a numerical model of thermal balance, which allows us to evaluate and to study the effect of water ponds on the urban thermal environment and energy load necessary for air conditioning. The water ponds have influences on temperature, moisture and radiation, implying complex phenomena whose modelling remain difficult.

\section{NUMERICAL MODELLING}

To express the different physicals phenomena that occur in urban spaces, a mathematical model of water ponds was developed. The model is based on coupling: the thermal model of the water pond and the airflow model of the surrounding air. Thermal modelling is carried out with SOLENE, simulation software of the solar and luminous radiation (Groleau 2000). Airflow modelling is achieved with FLUENT CFD commercial code, which allows the introduction of user-defined functions to enhance its standard features. Moreover, it allows the definition of a nonstructured grid, which is essential for the urban scenes modelling. We developed a procedure of coupling it with SOLENE. The thermal boundary conditions for the CFD code are given by SOLENE by using the same computational grid for surfaces.

\section{Thermal model of the water pond}

The thermal model of the water pond allows us to compute the temperature in the volume and on the surface of the water. This model is based on energy balance and takes into account the heat transfer by radiation, conduction, convection and the latent heat 
transfer due to water evaporation. It completes the models of wall and ground already developed (Vinet 2000). The water pond model is broken down into a number of basic components, each of which is represented by surface and interior nodes. The thermal balance applied in each node allows us to establish a set of differential equations solved by finite-difference method. The pond is modelled by considering three layers: a first layer representing the water, a second one corresponding to the bottom of the pond (i.e. concrete) and a third one corresponding to the ground (Figure 1). This last layer has a minimal depth of one meter, which corresponds to the reference temperature of the ground. This value of one meter represents the depth to which the daily temperature variations are damped (Landsberg 1981).

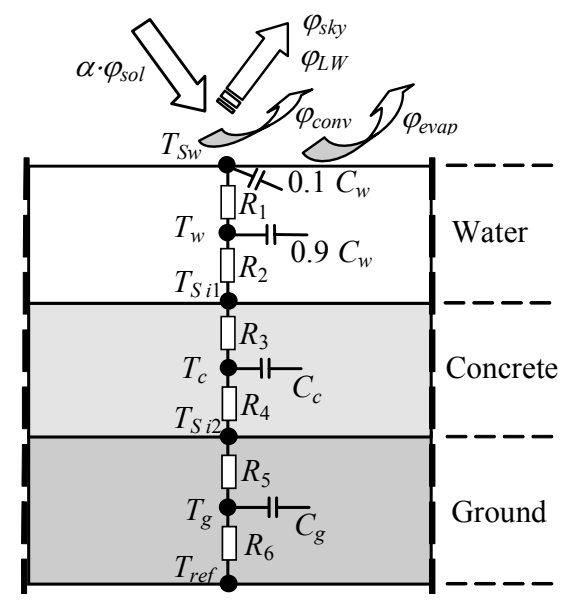

Figure 1: Thermal model of the water pond.

In the pond model, we use electrical analogy involving capacities and thermal resistances. $1 / 10^{\text {th }}$ from the total capacity of the first layer, $C_{w}$, was affected to the first node and the major part of the layer inertia, $9 / 10^{\text {th }}$, was concentrated to the second node (Figure 1), following the studies of sensitivity carried out using the Minerve model (Neveu 1984). For each layer of the model, we allocated the specific solar and thermal properties.

It is assumed that the conduction heat transfer is unidirectional and that each layer of the model is homogeneous; we consider as well that pond is permanently supplied with water. The heat transfer inside the solids and the fluids is carried out by conduction (Guyot 1996) which is modelled by thermal resistances.

On the water surface, the specific phenomena of evaporation are taken into account.

The temperatures of the surface and the various elements of the pond are obtained by applying the energy balance equation utilising, according to the node considered, radiation, convection, conduction and latent heat transfer.

\section{Conduction}

Fourier law is used to express the conduction heat transfer in each layer of the model:

$\varphi_{\text {cond }}=\frac{\lambda_{i}}{\Delta x_{i}}\left(T_{i}-T_{i-1}\right)$.

The layers of the model are divided into two parts ( $\Delta x$ is the distance between two successive nodes in the model layers). A condition of constant temperature is imposed at the bottom of the third layer.

\section{Evaporation}

If unsaturated air flows over the water surfaces, some water evaporates into the air. The same air flow or the water volume supplies the heat necessary for evaporation, obtaining the so-called evaporative cooling. These continuous phenomena of evaporation of water, due to water pond and vegetation, produce many daily climatic variations in the atmosphere. The cooling of the air due to water evaporation is proportional to the evaporative flow mass and is evaluated from the relation:

$\varphi_{\text {evap }}=L_{v} \cdot E$.

The latent heat of water vaporisation, $L_{v}$, is calculated by (Musy and Soutter, 1991):

$$
L_{v}=2499-2.386 \cdot \theta \text {. }
$$

Water evaporation depends on wind, atmospheric stability, and air humidity. If only a specific humidity is known at the reference level, water evaporation can be estimated by a bulk formula assuming that the air near the water surface is saturated at the water temperature and the evaporative flux is (Brutsaert 1982):

$$
E=\rho_{a} C_{e}\left(q_{s}-q_{a}\right) \mathbf{u}=C_{e}\left(d_{v s}-d_{v a}\right) \mathbf{u} .
$$

The density of the moist air is (Brutsaert 1982):

$$
\rho_{a}=\frac{p}{R_{d} T_{a}}\left(1-\frac{0.378 p_{v}}{p}\right) .
$$

Specific humidity, $q$, expressed in terms of atmospheric and partial pressure is equal to:

$$
q=\frac{\varepsilon \cdot p_{v}}{p-(1-\varepsilon) p_{v}}
$$

If we take into account the large difference between the atmospheric pressure and the partial pressure of 
the water vapour, we can use the following relation to determine the specific humidity:

$q=\varepsilon \frac{p_{v}}{p} ; q_{\text {sat }}=\varepsilon \frac{p_{v s a t}}{p}$

The saturating vapour pressure of water over a liquid surface, $p_{v s a t}(\mathrm{mb})$, increases with temperature, $t$, and according to Bolton (Jacobson 1999) is defined as:

$$
p_{v s a t}(t)=6.112 \exp \left(\frac{17.67 t}{t+243.5}\right)
$$

Water vapour pressure in the air, a function of relative humidity, $H R$, is equal to:

$$
p_{v a}\left(t_{a}\right)=H R \cdot p_{v s a t}\left(t_{a}\right)
$$

Finally, the evaporation flow mass, $E$, is:

$$
E=\rho_{a} C_{e} \frac{\varepsilon}{p}\left(p_{v s a t}\left(t_{S w}\right)-H R \cdot p_{v s a t}\left(t_{a}\right)\right) \mathbf{u}
$$

\section{Radiation heat transfer}

The modelling of radiation heat transfer in the urban scene is divided in two terms: one of them corresponds to the solar band (short-wave radiation) and the other corresponds to the thermal infrared band (long-wave or terrestrial radiation). Global solar contribution is first computed for each element of the water surface as a sum of the direct, diffuse and reflected irradiances under clear sky conditions. After that, this contribution is used to initialise a progressive refinement algorithm (Miguet et al., 1996) which treats the multiple reflections between surfaces of the urban scene (wall of building, ground, water pond) in order to obtain the net solar radiation flux. This procedure makes it possible to determine the radiosity, in each node of the surface grid (Antoine 1997):

$$
J_{i}=J_{0 i}+\rho_{i} \sum_{j=1}^{n} J_{j} \cdot F_{i j}
$$

where $J_{i}$ is the radiosity of element $i\left(\mathrm{~W} / \mathrm{m}^{2}\right), J_{0 i}$ the density of energy emitted by element $i\left(\mathrm{~W} / \mathrm{m}^{2}\right), \rho_{i}$ its reflectivity (fraction of incident energy reflected in the environment), $n$ the number of elementary surfaces, $d A_{i}$ of the environment, and $F_{i j}$ the view factor between element $i$ and the element $j$ (fraction of energy leaving the element $i$ and which reaches the element $j$ ):
$F_{i j}=\frac{1}{A_{i}} \int_{A_{i}} \int_{A_{j}} \frac{\cos \theta_{i} \cos \theta_{j} d A_{i} d A_{j}}{\pi l^{2}}$.

Long-wave radiative exchanges, $\varphi_{L W}$, between water surface and all facets of the urban scene and the sky are computed by using the surfaces view factor distribution, $F_{S w, j}$ :

$\varphi_{L W}=\sum_{j=1}^{n} \varepsilon_{S w} F_{S w, j} \sigma\left(T_{S w}^{4}-T_{S j}^{4}\right)$

Long-wave radiative exchanges between water surface and the sky are computed using sky view factor, $F_{S w, s k y}$ :

$\varphi_{s k y}=F_{S w, s k y}\left(\sigma \varepsilon_{S w} T_{S w}^{4}-L_{a}\right)$.

The radiation of the sky, $L_{a}$, is calculated with the following formula, according to Monteith and Unsworth (1991):

$$
L_{a}=5.5 T_{a}+213 .
$$

In the water pond model, we have not taken into account the possible reflections inside the water body.

\section{Energy balance of water pond}

In the preceding stages, we explained the terms involved in the energy balance. Now, we apply the equation of heat balance to each of the model nodes (Figure 1):

$$
C_{w} \frac{d T_{S w}}{d t}=\alpha \varphi_{s o l}-\varphi_{c o n d}-\varphi_{c o n v}-\varphi_{\text {evap }}-\varphi_{L W}-\varphi_{s k y}
$$

The energy balance applied to the surface node, gives:

$$
\begin{aligned}
\frac{C_{w}}{10} \frac{d T_{S w}}{d t}=\alpha & \cdot \varphi_{\text {sol }}-\varphi_{L W}-\varphi_{s k y} \\
& -\varphi_{\text {conv }}-\varphi_{\text {evap }}-\frac{1}{R_{1}}\left(T_{S w}-T_{w}\right)
\end{aligned}
$$

The energy balance applied to an interior node, for example to the water layer, gives:

$$
\frac{9 C_{w}}{10} \frac{d T_{w}}{d t}=\frac{1}{R_{1}}\left(T_{S w}-T_{w}\right)-\frac{1}{R_{2}}\left(T_{w}-T_{s i 1}\right) .
$$

The energy balance applied to the surface node of the layers, for example to the concrete surface, gives: 
$\frac{1}{R_{2}}\left(T_{w}-T_{S i 1}\right)-\frac{1}{R_{3}}\left(T_{S i 1}-T_{c}\right)=0$.

We adopted an implicit finite-difference approximation to solve the system of differential equations.

\section{CFD model}

In the pond model, we take into account the air flow near the water surface by considering that the water vapour in the air has the specific humidity $q_{a}$, the pressure $p_{v a}$, and that the initial temperature of the air $T_{M S}$, given by Weather Service. As a result of the water evaporation, the air flowing over the water surface may be considered to be saturated at a temperature equal to water temperature. There is simultaneously a heat transfer due to the temperature variation between water and air, and a mass transfer due to the gradient of the specific humidity of water vapour in the air. Latent heat transfer necessary for evaporation accompanies this mass transfer.

Computational Fluid Dynamics (CFD), based on the solution of continuity, energy, Navier-Stokes equations, conservation of a chemical species, $k-\varepsilon$ standard model of turbulence and under the Boussinesq hypothesis, can provide the air speed, temperatures and species fields. The boundary conditions are a logarithmic law profile for the incoming wind, derived from meteorological conditions and site location. The water surface temperature, computed with SOLENE software, is used as boundary condition for energy equation solved with FLUENT CFD code and wall law for the ground. Finally, air specific humidity for the surrounding air and for the water surface is used for species conservation.

The continuity equation is:

$\nabla \cdot(\rho \mathbf{u})=0$.

The momentum equation is:

$\frac{\partial \mathbf{u}}{\partial t}+(\mathbf{u} \cdot \nabla) \mathbf{u}=-\frac{\mathbf{1}}{\rho} \nabla p+v \nabla^{2} \mathbf{u}+\beta T \mathbf{g}$.

The energy equation, expressed in terms of enthalpy:

$\frac{\partial h}{\partial t}+(\mathbf{u} \cdot \nabla) h=D_{\mathrm{t}} \nabla \cdot(\nabla h)$.

The conservation of a chemical species is:

$\frac{\partial q}{\partial t}+(\mathbf{v} \cdot \nabla) q=D_{\mathrm{q}} \nabla \cdot(\nabla q)$.

\section{Methodology for coupling the models}

Our numerical model is thus based on coupling the simulation of the solar and thermal radiation and the simulation of air flow. By synthesising what we described above, the computation algorithm is as follows (Figure 2). After the initial computation of the radiosity in the solar band, the surface temperatures are initialised. Afterwards, these are used to evaluate radiosity in the long-wave radiation band. The values of radiosity thus obtained are introduced into the energy balance equation, which allows us the recalculation of temperatures; these new temperatures return and modify the radiosities.

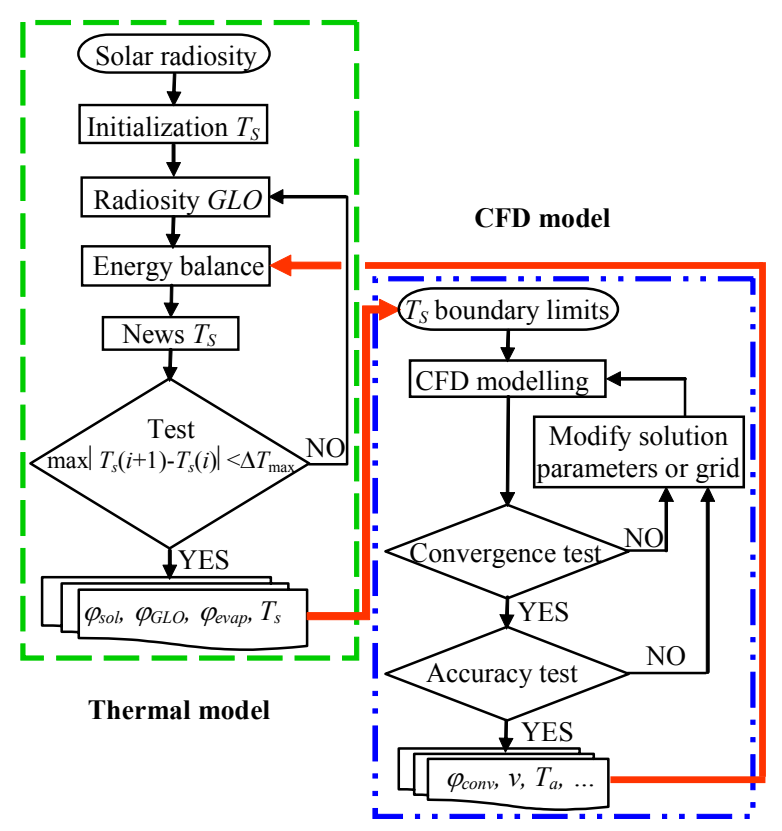

Figure 2: Pond model algorithm; models coupling.

The iterative computation process depends on the stop criterion whose desired precision is fixed by the user. At the end of the iterations, the temperatures of surfaces, solar net flows, infrared flows and the latent heat flow are known for each element of the urban scene (Figure 2).

At each simulation time $t$, the surface temperatures, computed by using the energy balance with the SOLENE software, are introduced into the CFD simulation, carried out with FLUENT code, like boundary conditions (temperature imposed on the wall). The modelling of flow makes it possible to obtain convective flows near the walls. These are then reintroduced in the heat balance established with SOLENE (Figure 2). This iterative procedure continues until the fixed criterion of convergence is reached. 


\section{Degree-Days, energy estimation}

The reduction of the outdoor air temperature due to the presence of the water ponds improves the outdoor air comfort and reduces the energy consumption for cooling. The estimation of the energy consumption reduction can be done by using the degree-day method.

Degree day values are valuable to analyse the impact of regional climate modification on energy need for heating and cooling of buildings. In this study, we analyse the amelioration of cooling energy load by using water pond surface. Cooling degree days are based on the day's average minus the balance point temperature that is $18.3^{\circ} \mathrm{C}$ (ASHRAE 1993). They relate the daily temperature to the energy demands for air conditioning.

If daily average values of outdoor temperature are used, the degree-days for cooling $D D_{C}\left(t_{b}\right)$ are obtained as (ASHRAE 1993):

$$
D D_{C}\left(t_{b}\right)=1 \text { day } \sum_{\text {days }}\left(t_{0}-t_{b}\right)
$$

Cooling energy consumption using degree-days is expressed as:

$Q_{C}=\frac{K_{t o t}}{\eta} D D_{C}\left(t_{b}\right)$.

\section{APPLICATION OF WATER POND MODEL}

The presence of the water pond improves the urban thermal environment in summer by cooling the air. Evaporation is always associated to the heat transfer necessary for this vaporization and coming either from the liquid, or from the air. The wind has an essential role on the process; it replaces the air saturated by drier air in the vicinity of water surface.

To illustrate our reasoning, we present comparative results obtained for a water surface and an asphalt surface. We determined the surface temperature of a water pond by applying the model of the water pond and that of the asphalt surface by applying the model of the ground. In this first approach, we considered that near the asphalt or water surface there is no building. Simulations were carried out for June 29 in conditions of clear sky for the town of Bucharest with weather data obtained with the Meteonorm software (Remund et al. 1999).

The considered surface has a length of $4 \mathrm{~m}$ and a width of $4 \mathrm{~m}$. The thicknesses of constituent layers of the models are given in Table 1.
Table 1

Layers thickness of the models

\begin{tabular}{|l|l|l|}
\hline \multicolumn{1}{|c|}{ LAYERS } & \multicolumn{1}{|c|}{$\begin{array}{c}\text { WATER POND } \\
\text { MODEL }\end{array}$} & \multicolumn{1}{|c|}{$\begin{array}{c}\text { GROUND } \\
\text { MODEL }\end{array}$} \\
\hline Water & $0.5 \mathrm{~m}$ & - \\
\hline Concrete & $0.2 \mathrm{~m}$ & - \\
\hline Asphalt & - & $0.2 \mathrm{~m}$ \\
\hline Ground & $1 \mathrm{~m}$ & $1 \mathrm{~m}$ \\
\hline
\end{tabular}

The solar and thermal properties specific to materials of each layer, are given in Table 2.

Table 2

Solar and thermal properties of materials

\begin{tabular}{|l|l|l|l|l|}
\hline PROPRIETIES & \multicolumn{1}{|c|}{ WATER } & CONCRET & ASPHALT & GROUND \\
\hline$\alpha$ & 0.7 & 0.7 & 0.9 & - \\
\hline $\mathrm{a}$ & 0.3 & 0.3 & 0.1 & - \\
\hline$\varepsilon_{S}$ & 0.9 & 0.9 & 0.95 & - \\
\hline$\lambda(\mathrm{W} / \mathrm{mK})$ & 0.58 & 0.9 & 0.75 & 0.25 \\
\hline$\rho(\mathrm{kg} / \mathrm{m} 3)$ & 1000 & 2300 & 2110 & 1600 \\
\hline$c_{p}(\mathrm{~J} / \mathrm{kgK})$ & 4200 & 960 & 920 & 890 \\
\hline
\end{tabular}

The temperatures of water and asphalt surfaces, computed with the thermal model implemented in SOLENE software are presented in Figure 3.

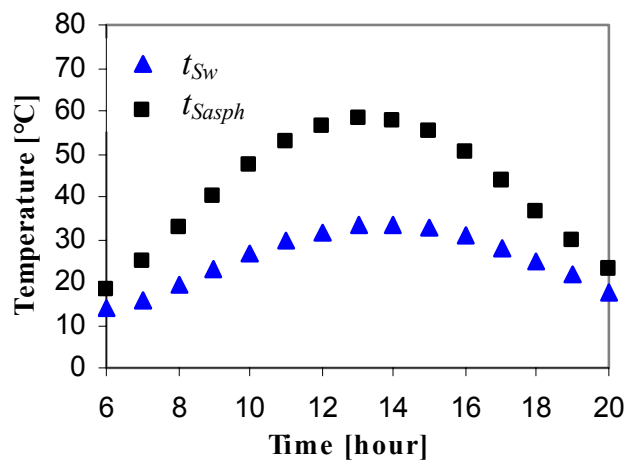

Figure 3: Water, asphalt surfaces temperatures.

These simulation results show that there are large differences between surface temperature of water and asphalt. This difference is from $4^{\circ} \mathrm{C}$ at $6 \mathrm{~h}$ to $25^{\circ} \mathrm{C}$ at $13 \mathrm{~h}$ when the maximum value of surface temperature are recorded, i.e. $33.2^{\circ} \mathrm{C}$ for water surface and $58.3^{\circ} \mathrm{C}$ for asphalt surface. This difference is due to water evaporation, with a latent heat flow from $115 \mathrm{Wm}^{-2}$ at $6 \mathrm{~h}$ to $431 \mathrm{Wm}^{-2}$ at $14 \mathrm{~h}$, as well as due to materials properties of the two surfaces, water and asphalts. The asphalte surface being quite dark, absorptivity equal to 0.9 (Table 2), it absorbs more solar radiation than the water surface, which absorptivity equals 0.7 .

\section{Initial and boundary condition for the CFD code}

Initial field values within the computation domain are chosen to hasten convergence. The initial wind speed is uniform $U_{0}=5 \mathrm{~m} \mathrm{~s}^{-1}$.

The boundary conditions for computation domain are illustrated in Figure 4. 


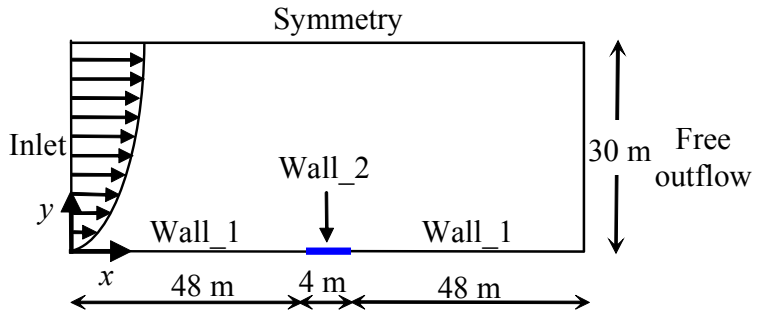

Figure 4: Dimensions and boundary conditions of domain considered.

\section{Inlet boundary conditions}

Inlet logarithmic wind profiles are chosen to simulate air flow over a surface with a roughness length assumed for ground surface of $y_{0}=5 \mathrm{~cm}$. The value of the wind speed at $10 \mathrm{~m}$ height is obtained from Meteonorm (Remund et al. 1999).

$u_{\text {in }}(y)=\frac{u_{*}}{k} \ln \left(\frac{y}{y_{0}}\right)$

$v_{\text {in }}(y)=0$

$T_{\text {in }}=300 \mathrm{~K}$

$q_{\text {in }}=0$

$k_{\text {in }}(y)=0.003 u_{0}^{2}$

$\varepsilon_{i n}=\frac{\mathrm{C}_{\mu}^{3 / 4} k_{i n}^{3 / 2}}{k y}$

\section{Wall boundary condition}

For the wall_1 boundary conditions, corresponding to the ground surface, we assume that the walls are adiabatic.

The wall 2 boundary conditions correspond to the water or asphalt surfaces. Temperature values for these two surfaces are obtained with SOLENE software by applying thermal model described beforehand. In the presence of water evaporation, a boundary condition in the case of water surface is required for vapour mass transport. This boundary condition is given by:

$q=q_{s}\left(T_{S w}\right)$.

The mass vapour transport equation 23 and energy equation 22 are coupled by means of boundary conditions.

Different profiles of temperature and water vapour fraction are presented at $13 \mathrm{~h}$ in Figure 5 and Figure 6.
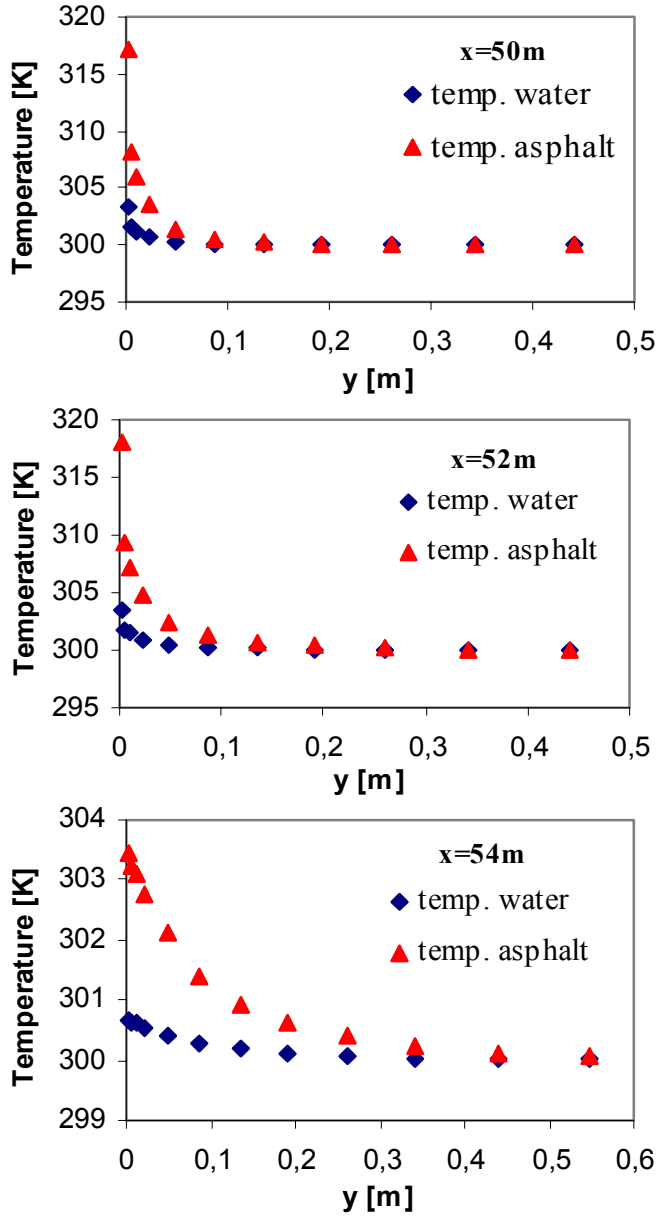

Figure 5: Air temperature near the water and asphalt surface for different $x$ value.

The air temperature near the water or asphalt surface is represented in Figure 5 for different horizontal distances $x$, equal to $50 \mathrm{~m}, 52 \mathrm{~m}$ and $54 \mathrm{~m}$. As expected, the air which flows near the asphalt surface has a higher temperature that the air which flows near water surface (Figure 5). Convective flow takes place due to temperature difference between air and water or asphalt surface. The value calculated for convective heat flux is $226 \mathrm{~W}$ for water surface and $1238 \mathrm{~W}$ for asphalt surface.

Figure 6 shows the molar water vapour evolution near the water surface.

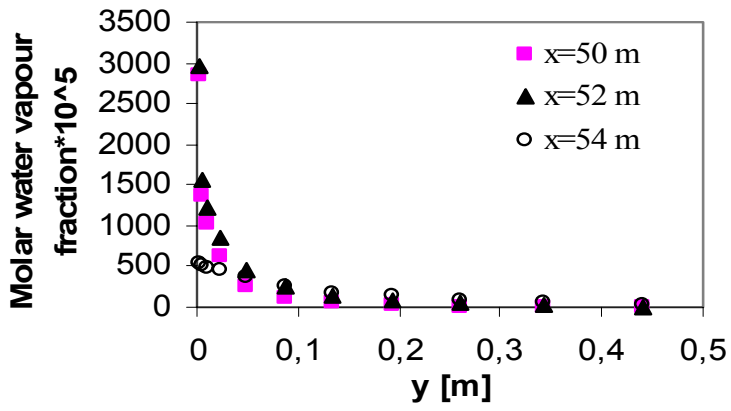

Figure 6: Molar water vapour fraction near the water surface. 
The presence of the water pond reduces air temperature by water evaporation. The estimation of this energy reduction is difficult to quantify. It depends on the ratio between the water surface and the urban surface, the geometry and materials of buildings, and the dominant winds. The model developed in this paper may be used to quantify the reduction of the energy consumption due to water surfaces in a given situation, e.g. a town square with buildings around a water pond. In the following investigations, we will take into account other sources of vapour which are present in particular at the level of the ground and vegetation surfaces. The final objective is to evaluate the total impact of the various sources of moisture on comfort in town and on the energy consumption of the buildings.

\section{CONCLUSIONS}

The physical phenomena, which take place in urban environment, can be modelled by the equations of radiation, conduction, convection to which we can associate an equation for evaporation. We presented a method of coupling these equations modelled in SOLENE and FLUENT software, which allows us to solve them. SOLENE calculates the surface temperatures of the elements of the model by taking into account the radiative, conductive and convective heat flow like those due to evaporation.

The surface temperatures, thus determined, are taken again for the calculation of convectif transfer in FLUENT software. FLUENT calculates the speed and pressure fields of the air and, in addition, it allows us to introduce species conservation equations. Convective flows are reintroduced in SOLENE in the energy balance equation and the iteration continues until obtaining a negligible variation of the temperature of surface between two steps of calculation. Then, the energy reduction can be estimated by using the degree hour method. Although this method is approximate, it has the advantage that the detailed energy calculations for buildings are not needed. This is particularly interesting for urban planning.

This procedure will be used in real cases in order to evaluate the robustness and the validity of the model. The finalised model will make it possible to measure the microclimatic impact of urban development plans as well as the level of comfort and the energy consummation of the buildings affected by these plans.

\section{REFERENCES}

Akbari, H., Davis, S., Dorsano, S., Huang, J., Winnett, S. (eds.), 1992. Cooling Our Communities: A Guidebook on Tree Planting and Light-Colored Surfacing, U.S. Environmental Protection Agency, Office of
Policy Analysis, Climate Change Division. Lawrence Berkeley National Laboratory Report No. LBL-31587.

Antoine, M. J.1997. Calcul des températures de parois pour les facettes du modèle géométrique d'un espace urbain ouvert. Contribution à l'établissement d'un modèle micro-climatique urbain, Nantes : CERMA, 34p.

ASHRAE, 1993. Handbook of Fundamental, SI Edition, Atlanta : ASHRAE, 5.1-5.15.

Bruse, M. 1999. Modelling and Strategies for improved urban climates, Invited Paper. Proc.of the Int. Conf. On Urban Climatology \& International Congress of Biometeorology, Sydney.

Brutsaert, W. 1982. Evaporation into the atmosphere, Dordrecht Holland : D. Reidel Publishing Company, 299p.

Givoni, B. 1991. Impact of planted areas on urban environmental quality: a review, Atmospheric Environment, Elsevier, 3, pp. 289-299.

Groleau, D. 2000. SOLENE, Un outil de simulation des éclairements solaires et lumineux dans les projets architecturaux et urbains, In : Colloque Artepa, Rouen, 8p.

Guyot, G. 1996. Climatologie de l'environnement De la plante aux écosystèmes,. Paris : Masson, $505 \mathrm{p}$.

Jacobson, M. Z. 1999. Fundamentals of Atmospheric Modeling, Cambridge University Press, New, $656 \mathrm{p}$.

Ken-Ichi, K. 1991. Evaporative cooling effects in hot and humid urban spaces, Kluwer Academic Publishers, 1991, proceedings "PLEA 91: Architecture and Urban Space, Ninth International PLEA Conference, Seville, Spain, pp 631-636.

Landsberg, H. 1981. The urban climate, Academic Press, London, UK ISBN 0-12-435960-4.

Mestayer, P. G. and Anquetin, S. 1994. Climatology of cities, In : Diffusion and Transport of Polluants in Atmosphéric Mesoscale Flow Fields. Atmospheric Sciences Library, Kluver Academic Publishers, pp. 165 - 189.

Miguet, F., Groleau, D., and Marenne, C. 1996. A combined sunlight and skylight tool for microclimatic analysis in urban architectures, Proc. of the 4th European Conf. on Solar Energy in Architecture and Urban Planning, Berlin, H.S. Stephen \& Associates UK, pp. 338-345. 
Monteith, J.L., and Unsworth, M.H. 1991. Principles of environmental physics. New York: Edward Arnold.

Musy, A. and Soutter, M. 1991. La physique du sol, Lausanne : Presses polytechniques et universitaires romandes. Collection Gérer l'environnement, $335 \mathrm{p}$.

Neveu, A. 1984. Etude d'un code d'évolution théorique d'une enveloppe de bâtiment (MINERVE), Thèse de doctorat.

Oke, T. R. 1982. The energetic basis of the urban heat island, Quart. J. R. Met. Soc., 108(455), pp.1-24.

Remund, J., Kunz, S. and Lang, R. 1999. METEONORM, Global meteorological database for solar energy and applied climatology, Meteotest, Fabrikstrasse 14, CH-3012 Bern, Switzerland, Swiss Federal Office of Energy, CH-3003 Bern.

Vinet, J. 2000. Contribution à la modélisation thermo-aéraulique du microclimat urbain. Caractérisation de l'impact de l'eau et de la végétation sur les conditions de confort en espaces extérieurs, Thèse de doctorat de l'Université de Nantes. Nantes : Université de Nantes, 2000, 245p.

\section{NOMENCLATURE}

\section{a Albedo (-)}

$C \quad$ Thermal capacity $\left(\mathrm{J} \mathrm{K}^{-1}\right)$

$C_{\mu} \quad$ Empirical constant, $C_{\mu}=0.09(-)$

$C_{e} \quad$ Evaporative heat transfer coefficient (Dalton number), $C_{e}=1.510-3(-)$

$D D_{C} \quad$ Cooling degree day $(\mathrm{K})$

$D_{q} \quad$ Mass diffusivity $\left(\mathrm{m}^{2} \mathrm{~s}^{-1}\right)$

$D_{t} \quad$ Thermal diffusivity $\left(\mathrm{m}^{2} \mathrm{~s}^{-1}\right)$

$d v \quad$ Absolute humidity (vapour density) $\left(\mathrm{kg} \mathrm{m}^{-3}\right)$

E Evaporating mass flux $\left(\mathrm{Kg} \mathrm{m}^{-2} \mathrm{~K}^{-1}\right)$

g Gravity acceleration $\left(\mathrm{m}^{2} \mathrm{~s}^{-1}\right)$

$H R$ Relative humidity (-)

$k \quad$ Turbulent energy $\left(\mathrm{m}^{2} \mathrm{~s}^{-2}\right)$
$K_{\text {tot }} \quad$ Total heat loss coefficient of the building $\left(\mathrm{W} \mathrm{K}^{-1}\right.$ )

$p \quad$ Atmospheric pressure (mb)

$p_{v} \quad$ Partial pressure of water vapour $(\mathrm{mb})$

$q \quad$ Specific humidity $\left(\mathrm{kg} \mathrm{kg}^{-1}\right)$

$Q_{C} \quad$ Cooling energy (W)

$R \quad$ Thermal resistance $\left(\mathrm{K} \mathrm{W}^{-1}\right)$

$R_{d} \quad$ Specific gas constant for dry air $\left(\mathrm{J} \mathrm{kg}^{-1} \mathrm{~K}^{-1}\right)$

$S \quad$ Surface $\left(\mathrm{m}^{2}\right)$

$T \quad$ Temperature (K)

u Wind speed $\left(\mathrm{m} \mathrm{s}^{-1}\right)$

Greek symbols

$v \quad$ Kinematic viscosity of air $\left(\mathrm{m}^{2} \mathrm{~s}^{-1}\right)$

$\varepsilon \quad$ Ratio of the mean molecular weight of water to the mean molecular weight of dry air (0.62197) (-)

$\alpha \quad$ Absorptivity (-)

$\varepsilon \quad$ Dissipation rate of $k\left(\mathrm{~m}^{2} \mathrm{~s}^{-3}\right)$

$\varphi \quad$ Flux density $\left(\mathrm{W} \mathrm{m}^{-2}\right)$

$\theta \quad$ Temperature $\left({ }^{\circ} \mathrm{C}\right)$

$\lambda \quad$ Thermal conductivity $\left(\mathrm{W} \mathrm{m}^{-1} \mathrm{~K}^{-1}\right)$

$\beta \quad$ Thermal expansion coefficient $\left(\mathrm{K}^{-1}\right)$

$\eta \quad$ Efficiency of the cooling system (-)

$\varepsilon_{S} \quad$ Emissivity of external surface (-)

$\rho_{a} \quad$ Density of the moist air at 10 meters $\left(\mathrm{kg} \mathrm{m}^{-3}\right)$

$\sigma \quad$ Stefan-Boltzmann constant $\left(\mathrm{W} \mathrm{m}^{-2} \mathrm{~K}^{-4}\right)$

Subscripts

a Air

asph Asphalt

$b \quad$ Balance

c Contrite

cond Conduction

conv Convection

evap Evaporation

g Ground

$i \quad$ Interior

$L W \quad$ Long wave

ref Reference

$s \quad$ Saturation

$S \quad$ Surface

sol Solar

$w \quad$ Water 